Technical Note

\title{
Open beam dosimetric characteristics of True Beam medical linear accelerator with flattening filter (WFF) and flattening filter free (FFF) beam
}

\author{
Karthick Raj MANI ${ }^{1,2, a}$, Md Anisuzzaman BHUIYAN ${ }^{2}$, Md. Shakilur RAHMAN ${ }^{3}$, S. M. Azharur ISLAM ${ }^{1}$ \\ ${ }^{1}$ Department of Physics, Jahangirnagar University, Savar, Dhaka - 1342, Bangladesh \\ ${ }^{2}$ Department of Radiation Oncology, United Hospital, Gulshan, Dhaka - 1212, Bangladesh \\ ${ }^{3}$ Secondary Standard Dosimetry Laboratory, Institute of Nuclear Science and Technology, Bangladesh Atomic Energy \\ Commission, Savar, Dhaka, Bangladesh \\ ${ }^{a}$ E-mail address: karthickrajmani@gmail.com
}

(received 25 July 2017; revised 19 November 2017, 25 January 2018, 18 April 2018; accepted 18 April 2018)

\begin{abstract}
True Beam medical linear accelerator is capable of delivering flattening filter free (FFF) and with flattening filter (WFF) photon beams. True Beam linear accelerator is equipped with five photon beam energies (6 FFF, $6 \mathrm{WFF}, 10$ FFF, $10 \mathrm{WFF}$ and $15 \mathrm{WFF}$ ) as well as six electron beam energies (6 MeV, $9 \mathrm{MeV}, 12 \mathrm{MeV}, 15 \mathrm{MeV}$ and $18 \mathrm{MeV})$. The maximum dose rate for the $6 \mathrm{WFF}, 10 \mathrm{WFF}$ and $15 \mathrm{WFF}$ is $600 \mathrm{MU} / \mathrm{min}$, whereas $6 \mathrm{FFF}$ has a maximum dose rate of $1400 \mathrm{MU} / \mathrm{min}$ and $10 \mathrm{FFF}$ with a maximum dose rate of $2400 \mathrm{MU} / \mathrm{min}$. In this report we discussed the open beam dosimetric characteristics of True Beam medical linear accelerator with FFF and WFF beam. All the dosimetric data (i.e. depth dose, cross-line profiles, diagonal profiles, output factors, MLC transmission, etc.) for $6 \mathrm{MV}, 6 \mathrm{FFF}, 10 \mathrm{MV}$, $10 \mathrm{FFF}$ and $15 \mathrm{MV}$ were measured and compared with the published data of the True Beam. Multiple detectors were used in order to obtain a consistent dataset. The measured data has a good consistency with the reference golden beam data. The measured beam quality index for all the beams are in good agreement with the published data. The percentage depth dose at $10 \mathrm{~cm}$ depth of all the available photon beams was within the tolerance of the Varian acceptance specification. The dosimetric data shows consistent and comparable results with the published data of other True Beam linear accelerators. The dosimetric data provide us an appreciated perception and consistent among the published data and may be used for future references.
\end{abstract}

\section{Introduction}

True Beam (M/S Varian Medical Systems, Palo Alto, CA) is the state-of-the-art modern Medical Linear Accelerator commercially available with millennium-120 leaf multi-leaf collimator (True Beam) or Varian high definition (HD) multileaf collimators (True Beam STx). True Beam STx model is a dedicated machine for stereotactic radiotherapy with the Varian HD MLC, which has central $8 \mathrm{~cm}$ (32 leaf pairs) of $0.25 \mathrm{~cm}$ MLC leaf width and peripheral 28 leafs with $0.5 \mathrm{~cm}$ leaf width at isocenter, whereas True Beam model has a millennium - 120 MLC has central $20 \mathrm{~cm}$ (40 pairs) with $0.5 \mathrm{~cm}$ leaf width and peripheral 20 leafs with $1 \mathrm{~cm}$ leaf width at isocenter. At United Hospital, Dhaka, Bangladesh we have commissioned the first True Beam Linear Accelerator and started the clinical services from November 2013. In this report, we would like to share our dosimetric data of the True Beam linear accelerator with flattening filter (WFF) and flattening filter free (FFF) beam. True Beam linear accelerator is equipped with 5 photon beam energies (6 FFF, 6 WFF, 10 FFF, $10 \mathrm{WFF}$ and $15 \mathrm{WFF}$ ) and 6 electron energies (6 MeV, $9 \mathrm{MeV}, 12 \mathrm{MeV}, 15 \mathrm{MeV}$ and 18 $\mathrm{MeV})$. The maximum dose rate for the $6 \mathrm{WFF}, 10 \mathrm{WFF}$ and 15
WFF is $600 \mathrm{MU} / \mathrm{min}$, whereas $6 \mathrm{FFF}$ has a maximum dose rate of $1400 \mathrm{MU} / \mathrm{min}$ and $10 \mathrm{FFF}$ with a maximum dose rate of $2400 \mathrm{MU} / \mathrm{min}$.

The 6 FFF and 10 FFF mode has a higher dose rate due to the removal of the flattening filter, which results in reduced head scatter from the linear accelerator head compared to the flatten beam. FFF beam also has a beam softening compare to the flattened beam due to the absence of the flattening filter, which results in the lesser dose outside the field edges. The carousel system has been modified in the True Beam to accommodate more photon and electron beam energies [1].

In this report, we would like to summarize the open beam dosimetric characteristics (i.e., depth dose, cross-line profiles, diagonal profiles, output factors, MLC transmission, etc.,) of True Beam medical linear accelerator.

\section{Range of measured data}

The dosimetric parameters and the range of the measured data for $6 \mathrm{MV}, 6 \mathrm{FFF}, 10 \mathrm{MV}, 10 \mathrm{FFF}$ and $15 \mathrm{MV}$ were listed in the Table 1. 
Table 1. Dosimetric parameters and its range

\begin{tabular}{cccc}
\hline \hline S.No & Parameters & Field size $\left.\mathbf{( c m}^{\mathbf{2}}\right)$ & Depth \\
\hline 1. & Percentage depth dose & $1 \times 1$ to $40 \times 40$ & 0 to $31 \mathrm{~cm}$ \\
2. & Cross-line profile & $1 \times 1$ to $40 \times 40$ & $($ Dmax, $5 \mathrm{~cm}, 10 \mathrm{~cm}, 20 \mathrm{~cm} \mathrm{\&} 30 \mathrm{~cm})$ \\
3. & Diagonal profile & $40 \times 40$ & $($ Dmax, $5 \mathrm{~cm}, 10 \mathrm{~cm}, 20 \mathrm{~cm} \mathrm{\&} 30 \mathrm{~cm})$ \\
4. & Output factor & $1 \times 1$ to $40 \times 40$ & SSD technique detector at $10 \mathrm{~cm}$ depth \\
5. & MLC leaf transmission & $10 \times 10$ & SAD technique detector at $10 \mathrm{~cm}$ depth \\
6. & Jaws transmission & $10 \times 10$ & SAD technique detector at $10 \mathrm{~cm}$ depth \\
7. & Dosimetric leaf gap & Not Applicable & SAD technique detector at $10 \mathrm{~cm}$ depth \\
8. & Absolute dosimetry & $10 \times 10$ & SSD technique detector at $10 \mathrm{~cm}$ depth \\
\hline \hline
\end{tabular}

Table 2. Physical Characteristics of Semiconductor detectors

\begin{tabular}{|c|c|c|c|c|c|c|c|}
\hline Detector Type & Stem material & $\begin{array}{c}\text { Active area } \\
\text { diameter }(\mathbf{m m})\end{array}$ & $\begin{array}{l}\text { Active volume } \\
\text { thickness (mm) }\end{array}$ & $\begin{array}{c}\text { Head diameter } \\
(\mathrm{mm})\end{array}$ & $\begin{array}{c}\begin{array}{c}\text { Head length } \\
(\mathrm{mm})\end{array} \\
\end{array}$ & $\begin{array}{c}\text { Stem diameter } \\
(\mathrm{mm})\end{array}$ & $\begin{array}{c}\text { Waterproof } \\
\text { Y / N } \\
\end{array}$ \\
\hline PFD $3^{\mathrm{G}}-\mathrm{pSi}$ & Stainless Steel & 1.6 & 0.08 & 7.2 & 17 & 4.0 & $\mathrm{Y}$ \\
\hline $\mathrm{EFD} 3^{\mathrm{G}}-\mathrm{pSi}$ & Stainless Steel & 1.6 & 0.08 & 7.2 & 17 & 4.0 & $\mathrm{Y}$ \\
\hline $\mathrm{SFD} 3^{\mathrm{G}}-\mathrm{pSi}$ & Stainless Steel & 0.6 & 0.04 & 4.0 & 15 & 4.0 & $\mathrm{Y}$ \\
\hline RFD $3^{\mathrm{G}}-\mathrm{pSi}$ & ABS and epoxy & 1.6 & 0.08 & 5.0 & 90 & n.a & $\mathrm{N}$ \\
\hline
\end{tabular}

Table 3. Physical Characteristics of Ionization chambers

\begin{tabular}{|c|c|c|c|c|c|c|c|}
\hline Detector Type & $\begin{array}{c}\text { Active volume } \\
\left(\mathrm{cm}^{3}\right)\end{array}$ & $\begin{array}{r}\text { Total active } \\
\text { length }(\mathrm{mm}) \\
\end{array}$ & $\begin{array}{c}\text { Diameter of central } \\
\text { electrode }(\mathrm{mm})\end{array}$ & Wall material & $\begin{array}{c}\text { Wall thickness } \\
\left(\mathrm{g} / \mathrm{cm}^{2}\right)\end{array}$ & $\begin{array}{c}\text { Central electrode } \\
\text { material }\end{array}$ & $\begin{array}{c}\text { Waterproof } \\
\text { Y / N } \\
\end{array}$ \\
\hline FC65-G & 0.65 & 23 & 1.0 & Graphite & 0.070 & Aluminum & $\mathrm{Y}$ \\
\hline $\mathrm{CC} 13$ & 0.13 & 10 & 1.0 & C-552 & 0.070 & C-552 & $\mathrm{Y}$ \\
\hline $\mathrm{CC} 01$ & 0.01 & 3.6 & 0.35 & C-552 & 0.088 & Steel & $\mathrm{Y}$ \\
\hline
\end{tabular}

\section{Detectors and phantom setup}

All the measurements were performed using IBA dosimetry system, the relative dosimetry (i.e., Percentage depth dose (PDD), cross-line profile, diagonal profile, output factor) were measured in the IBA Blue Phantom 2 radiation field analyzer. The absolute dosimetry for all the photon beam energies was performed using the WP 34 absolute dosimetry phantom (IBA, $\mathrm{GmbH}$, Germany). The MLC leaf transmission, secondary jaw transmission and dosimetric leaf gap for all the available photon energies were measured using the Solid water SP34 white Polystyrene phantom along with the FC65-G ionization chamber. The Blue Phantom Radiation field analyzer has a measurable dimension of $480 \mathrm{~mm} \times 480 \mathrm{~mm} \times 410 \mathrm{~mm}$ (length $\mathrm{x}$ width $\mathrm{x}$ height) with a position accuracy, reproducibility and position within $0.1 \mathrm{~mm}$. It has a maximum scanning speed of $50 \mathrm{~mm} / \mathrm{sec}$. The Blue phantom is connected to the common control unit using a custom trigger interface of RS 485 cable, which has a bias voltage range from $\pm 50 \mathrm{~V}$ to $\pm 500 \mathrm{~V}$. The Radiation field analyzer also connected to a water reservoir of 220 liter capacity attached with a dual pump system.

The semiconductor detectors and the ionization chamber used for the beam data commissioning and its physical characteristics were listed in the Table $\mathbf{2}$ and Table 3.

A semiconductor detector based on silicon gives a signal which is high compared to the signal from an air filled ionization chamber with the same volume. There are two reasons, (i) The energy required to produce an ion-pair in silicon detector is approximately $3.6 \mathrm{eV}$ and the corresponding energy required for an air-filled ionization chamber is about 33 $\mathrm{eV}$, (ii) The density of the silicon is about 2000 times higher than that of the air.

The ionization chambers are the real choice for the absolute dosimetry measurements and also used in the relative measurements for PDD and profile measurements for the field size larger than $5 \times 5 \mathrm{~cm}^{2}$, the ionization chamber may overestimate the beam penumbra compared to the actual particularly in small fields.

\section{Reference detector placement for relative dosimetry measurements}

The photon and electron beam produced in the medical linear accelerator are pulsed beams, which causes the signal fluctuation by the pulse beam which may end-up in the unsmooth profile or PDD curves. This fluctuation can be avoided by two methods, the first method is taking several measurements and average it, this can be an accurate method, but highly time consuming [2]. The second method is using an another detector as a reference detector placed in the air inside the radiation field edge, since the reference detector and the field detector subject to the same fluctuations, the fluctuation can be mathematically suppressed, thus giving a stable signal acquisition[3].

As fields approach smaller sizes, in case of stereotactic fields, the maintenance of the reference will be more difficult, and every time need to enter the linear accelerator room to change the reference detector position to avoid the saturation 
and renormalization is required for every time change in the reference detector position.

We used a simple method [4] to solve this issue by placing the edge of the reference detector in the radiation field above the secondary jaws and below the primary collimator as shown in the Figure 1. This method helps us to save time as well as avoid the reference detector interference over the field detector for the smaller fields.

\section{Percentage depth dose}

The PDD measurements of the photon beam energies were carried out using the $\mathrm{CC} 01$ / CC13 ionization chamber for the filed size from $1 \times 1 \mathrm{~cm}^{2}$ to $40 \times 40 \mathrm{~cm}^{2}$. During the PDD measurements for the photon beams, the effective point of measurements must carefully adjust to obtain proper PDD. Cylindrical ionization chambers produce perturbations in the medium, and hence the point of measurement is not accurately defined in photon and electron beams [5]. The gradient perturbation is often corrected by a shift method depending on the type of ion chamber. PDDs were measured according to the IAEA TRS-398 recommendations. PDD scanning direction should be always from bottom to the top, to avoid the wobble of the water surface. The PDD measurements were done using SSD of $100 \mathrm{~cm}$ on the phantom surface for the depth range of 0 to $31 \mathrm{~cm}$. The reference detector is placed above the secondary collimator as shown in the Figure 1. The dose rate for $6 \mathrm{WFF}$, $10 \mathrm{WFF}$ and $15 \mathrm{WFF}$ were kept $400 \mathrm{MU} / \mathrm{min}$ and for $6 \mathrm{FFF}$ and $10 \mathrm{FFF}$ the dose rates were $800 \mathrm{MU} / \mathrm{min}$ during the PDD measurements. During the PDD measurements the step size were kept $1 \mathrm{~mm}$ for first 0 to $50 \mathrm{~mm}$, remaining $50 \mathrm{~mm}$ to 310 $\mathrm{mm}$ were measured with $2.5 \mathrm{~mm}$ grid size and the measurement time were $0.5 \mathrm{sec}$ per points. All the PDD data were normalized to $10 \times 10 \mathrm{~cm}^{2}$ field size at Depth of Maximum $\left(D_{\max }\right)$ for all the available photon beam energies, hence we can convert the PDD data to the eclipse RTPS file without any renormalization.

\section{Cross-line profiles}

Cross-line profiles for various field sizes from $1 \mathrm{x} 1 \mathrm{~cm}^{2}$ to $5 \mathrm{x}$ $5 \mathrm{~cm}^{2}$ were measured using the SFD detector and from the field size $5 \times 5 \mathrm{~cm}^{2}$ to $40 \times 40 \mathrm{~cm}^{2}$ were measured with $\mathrm{CC} 13$ ionization chamber for all the photon beam energies with the same dose rate specified in the PDD at five different depths $\left(D_{\max }, 5 \mathrm{~cm}, 10 \mathrm{~cm}, 20 \mathrm{~cm} \& 30 \mathrm{~cm}\right.$ ). The field size $5 \times 5 \mathrm{~cm}^{2}$ measured with the SFD and CC13 were cross checked for the deviation due to the setup errors. All the cross-line profiles were acquired with minimum of $5 \mathrm{~cm}$ outside the absolute penumbra on either side to account for the accurate calculation outside the radiation fields. The reference detector was also placed above the secondary jaws for all the cross-line measurements. Measuring all cross-line profiles with a diode is equally acceptable, as long as care is taken for the accuracy of the measured profile outside the field in the profile tail region as well as inside the field. (a)

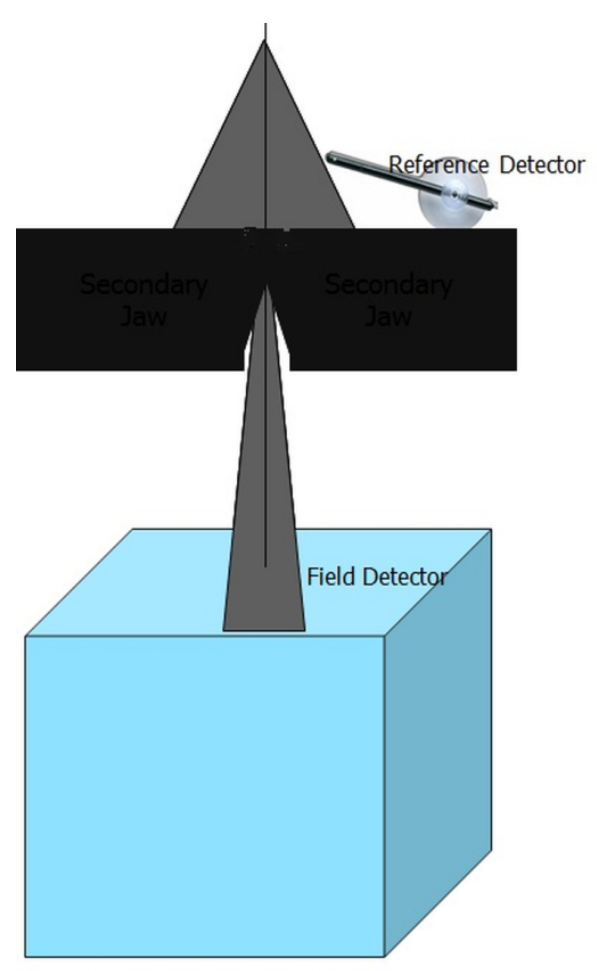

(b)

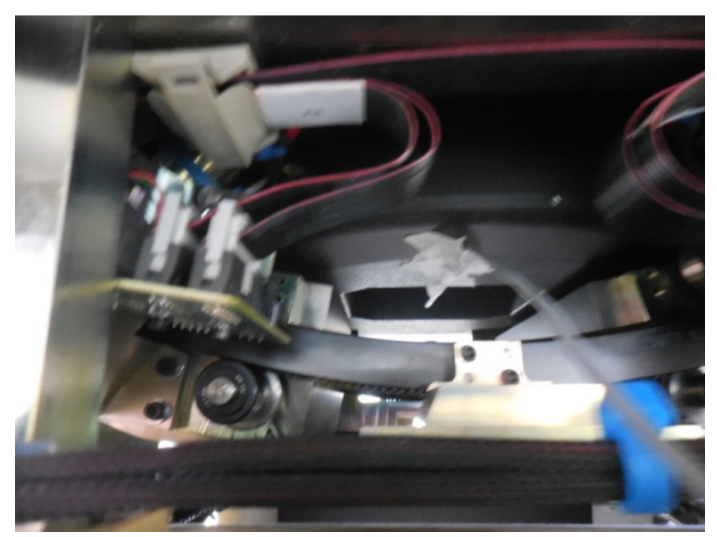

Figure 1. (a) illustrates the reference chamber placement above the secondary jaws and below the primary collimator (b) photo graph of the reference detector placement above the secondary jaw.

\section{Diagonal profiles}

For the Eclipse photon beam data configuration we required the diagonal profiles only for the filed size $40 \times 40 \mathrm{~cm}^{2}$ at various depths $\left(D_{\max }, 5 \mathrm{~cm}, 10 \mathrm{~cm}, 20 \mathrm{~cm} \mathrm{\&} 30 \mathrm{~cm}\right)$. The dimension of the Blue phantom and most of the commercial radiation field analyzer were not capable of measuring the full profile due to its limitation in the dimension, hence try to take the half profile by moving the radiation filed analyzer to one side with adequate scatter for the detector and converted the half profile to the full profile using the omnipro accept software option of make symmetric using right or left side. 


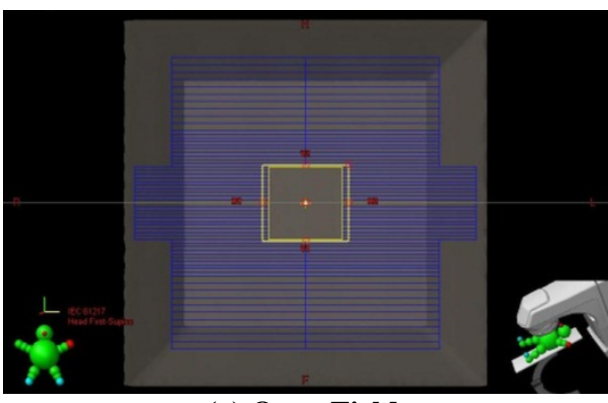

(a) Open Field

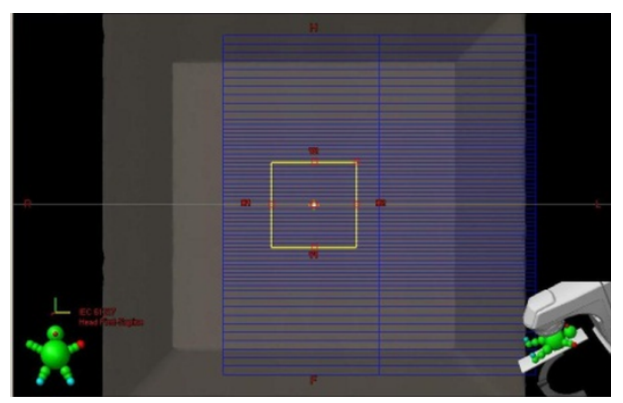

(b) B Bank transmission MLC position

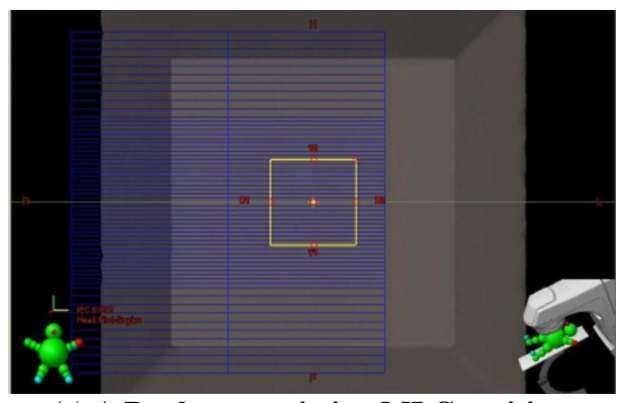

(c) A Bank transmission MLC position

Figure 2. (a) open field MLC $10 \times 10 \mathrm{~cm}^{2}$, (b) B Bank transmission MLC position, and (c) A Bank transmission MLC position.

\section{Output factors}

Output factors were measured using two detectors the EFD and the $\mathrm{CC} 13$ ionization chamber at $10 \mathrm{~cm}$ depth using the SAD technique. Output factors were measured from $1 \times 1 \mathrm{~cm}^{2}$ to 40 $\mathrm{x} 40 \mathrm{~cm}^{2}$, using two types of detectors. Small fields (where at least one field dimension is smaller than $4 \mathrm{~cm}$ ) were measured with the diode. Larger fields were measured with the ionization chamber. According to this definition, a $3 \times 40 \mathrm{~cm}^{2}$ field still belongs to the "small fields", whereas a $5 \times 5 \mathrm{~cm}^{2}$ field is a "large field". The 4 x $4 \mathrm{~cm}^{2}$ used as a cross-reference field for both the detectors and it's only for cross calibration. EFD are shielded diodes and recommended for the small filed output factor measurements, the EFD is directly connected to the IBA Dose 1 electrometer without applying any voltage you can measure the charge produced in EFD for the output factors.

\section{Jaw transmission}

Jaw transmission measured preferably with a large volume chamber using a solid or water phantom with SAD technique. Irradiate at-least $300 \mathrm{MU}$ for the open field size of $10 \times 10 \mathrm{~cm}^{2}$ and note down the value, we need to measure the secondary jaws independently using the asymmetric jaw override, for e.g the $\mathrm{Y} 1$ jaw can override the isocenter by $10 \mathrm{~cm}$, to determine the $Y 1$ jaw transmission keep the $X$ jaw symmetric $10 \mathrm{~cm}, Y 2$ jaw $10.5 \mathrm{~cm}$ and $\mathrm{Y} 1$ jaw at $-10 \mathrm{~cm}$. The ratio between the readings with $\mathrm{Y} 1$ jaw to the open field is the $\mathrm{Y} 1$ jaw transmission; repeat the same procedure for $\mathrm{Y} 2$ jaw. $\mathrm{X}$ jaw transmission measurement is slightly trickier, since $\mathrm{X}$ jaw can override only $2 \mathrm{~cm}$ over the central axis, try to move the ionization chamber offset by $5 \mathrm{~cm}$ such that your $\mathrm{X} 1$ jaw at $-2 \mathrm{~cm}$, keeping only the $\mathrm{X} 1$ jaw just above the ionization chamber and measure the transmission factor.

\section{MLC leaf transmissions}

MLC leaf transmission were measured using a large volume chamber preferably farmer chamber, with a water phantom or slab phantom using SAD technique, by keeping the SSD $90 \mathrm{~cm}$ on the surface of the phantom and the detector at $10 \mathrm{~cm}$ at the isocenter. Make sure the detector is placed along the perpendicular direction of the MLC leaf. The open $10 \times 10 \mathrm{~cm}^{2}$ field was irradiated to $300 \mathrm{MU}$ and kept as a reference reading and the transmission of the A and the B bank were taken.

The percentage ratio between the average A and B bank transmission to the open field is calculated as a MLC transmission factor. The same procedures were repeated for all the available photon beam energies. The MLC portal for the open beam, MLC A bank and the B Bank were shown in the Figure 2.

$R_{T}=\left\{\frac{R_{T, A}+R_{T, B}}{2}\right\}$ Eq. 1

where $R_{T}$ is the average tranmission of the bank ' $\mathrm{A}$ ' and Bank 'B' MLC, $R_{T, A}$ is the tranmission factor the the 'A' Bank and the $R_{T, B}$ is the tranmission factor the ' $\mathrm{B}$ ' Bank respectively.

\section{Dosimetric Leaf Gap}

The dosimetric leaf gap describes an effective leaf shift due to the round leaf end design of most MLCs. The dynamic leaf gap is defined as a gap between light and radiation fields, and can be measured by extrapolating the size of static or dynamic fields formed by MLC leaves to the size under which the measured dose equals the MLC leakage [6]. To improve the agreement between treatment planning predicted fluence and measured fluence, we need to tune the dosimetric leaf gap from the measured dynamic leaf gap [5]. Dosimetric leaf gap accounts for dosimetric effect of rounded leaves and it applies both for dynamic and static MLC treatment mode.

This value is determined by using Varian MLC files or digital image communication in medicine (DICOM) files provided by Varian to measure the isocenter doses for sliding gaps with different widths The Varian DICOM file contains fields with sliding MLC gap. 2, 4, 6, 10, 14, 16, 20 mm gap sizes are provided. The gap moves from $-60 \mathrm{~mm}$ to $+60 \mathrm{~mm}$ with constant speed with respect to MU. The leaves position is defined every $10 \mathrm{~mm}$ by a control point. The resulting fluence is uniform within the field size of $10 \times 10 \mathrm{~cm}^{2}$. Measure the readings for the different gap files and document it. Calculate contribution of the average MLC leaf transmission to the gap reading $\left(R_{g T}\right)$ for each gap $g$. 


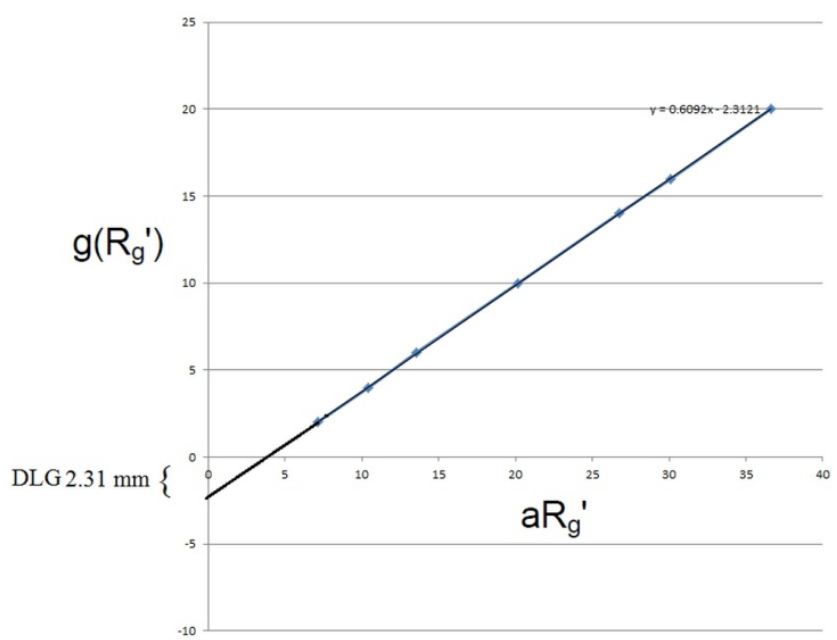

Figure 3. Determination of Dosimetric Leaf Gap

The contribution of transmission to gap reading is defined as:

$R_{g T}=R_{T}\left[1-\frac{g[\mathrm{~mm}]}{120[\mathrm{~mm}]}\right]$

Eq. 2

where $R_{T}$ is the average tranmission of the bank 'A' and Bank ' $\mathrm{B}$ ' MLC, $120[\mathrm{~mm}]$ is the leaf travel distance used in provided DICOM files. Calculate corrected gap reading for each gap $g$. Corrected gap $R_{g}$ is defined as:

$R_{g^{\prime}}=R_{g}-R_{g T}$

Eq. 3

Fit a linear function $g\left(R_{g^{\prime}}\right)=a R_{g^{\prime}}+b$ to points given by gap size $g$ and corrected gap reading $R_{g^{\prime}}$. Write down the intercept of the fitted function $(b)$. The absolute value of ' $b$ ' is the Dosimetric Leaf Gap as shown in the Figure 3. The measured dose $D$ can approximately be described by the linear function.

\section{Absolute Dosimetry}

Absolute dosimetry for all the available photon energies was determined using the IAEA Technical Report Series (TRS-398) [7]. Beam quality index were measured for all the five photon energies using the $\mathrm{TPR}_{20,10}$ and absolute dose determination were done at $10 \mathrm{~cm}$ depth using $\mathrm{SSD}$ technique. All the measurements were carried out using the IBA WP 34 water phantom with farmer $0.65 \mathrm{cc}$ (FC 65-G) chamber. The meter readings were corrected for temperature-pressure correction, polarity effect and recombination effect. The corrected meter readings were multiplied using the absolute dose to water calibration factor $\left(N_{D, w, Q_{0}}\right)$ provided by the secondary standard dosimetry lab along with the appropriate $\mathrm{K}_{\mathrm{Q}}$ according to the beam quality. The machine was tuned to deliver $1 \mathrm{cGy} / \mathrm{MU}$ at SSD technique at $D_{\max }$ for all the available photon energies and kept as a baseline.

$D_{w, Q}=M_{Q} N_{D, w, Q_{0}} k_{Q, Q_{0}}$

Eq. 4

Some institutes still using the AAPM TG-51 protocol for clinical reference dosimetry of high-energy photon and electron beams [8] which is released in 1999, both the TG-51 and TRS-398 conception and the basic theory model is the same, except there is a small change in the measurement of beam quality measurement in TG-51 compared to TRS-398, which is to use the $1 \mathrm{~mm}$ lead foil to avoid the electron contamination for $10 \mathrm{MV}$ and above.

Major dosimetry issues for FFF is with the active ion chamber volume are (i) the FFF beams are not flat, hence uniformity correction need to be applied, (ii) FFF beams are not well filtered, so the large spectral variation affects the beam spectrum and beam quality and (iii) FFF beams are less attenuated and hence the increase in the doserate may increase the ion combination correction factor.

The ion recombination correction factor $\left(\mathrm{K}_{\mathrm{s}}\right)$ is accounted to correct the incomplete collection of charges and it is directly proportional to the dose per pulse of the machine output [9]. For the FFF beams, the doserate increases around 2.5 to 4 times of the conventional flatten photon beam doserates. But, $\mathrm{K}_{\mathrm{s}}$ correction factor were within $2 \%$ from the unity $\left(1 \leq \mathrm{K}_{\mathrm{s}}<\right.$ 1.02) for Farmer, PinPoint and Parallel Plate chamber for 6 $\mathrm{MV}$ and $10 \mathrm{MV}$ FFF beams [9]. The $\mathrm{K}_{\mathrm{s}}$ correction factor will increase with the increase in the dose per pulse.

\section{Results and discussion}

PDD measurements for all the photon beam energies were acquired from the field size $1 \times 1 \mathrm{~cm}^{2}$ to $40 \times 40 \mathrm{~cm}^{2}$. Beam softening were observed for the $6 \mathrm{FFF}(2.7 \%)$ and $10 \mathrm{FFF}$ $(2.7 \%)$ beam compared to the $6 \mathrm{MV}$ and $10 \mathrm{MV}$ beams with flattening filter for $10 \times 10 \mathrm{~cm}^{2}$ field size PDD at $10 \mathrm{~cm}$ depth.

The measured PDD for $10 \times 10 \mathrm{~cm}^{2}$ for all the available energies were illustrated in the Figure 4. The PDD for the field size $1 \times 1 \mathrm{~cm}^{2}$ to $40 \times 40 \mathrm{~cm}^{2}$ for $6 \mathrm{MV}$ is listed in the Figure 5. The PDD for $10 \times 10 \mathrm{~cm}^{2}$ reference field size at 10 $\mathrm{cm}$ depth for the photon beams $6 \mathrm{FFF}, 6 \mathrm{MV}, 10 \mathrm{FFF}, 10 \mathrm{MV}$ and $15 \mathrm{MV}$ were $64.4 \%, 67.1 \%, 71.8 \%, 74.5 \%$ and $77.3 \%$ respectively. Figure 4 clearly illustrates that 6 FFF has a softer beam compare to the $6 \mathrm{MV}$ beam and similarly the $10 \mathrm{FFF}$ has a beam softening compared to the $10 \mathrm{MV}$ beam. The PDD of all the flatten beam were compared with British Journal of Radiology Supplement 25 [10] which was released in 1996, BJR reference value for PDD at $10 \mathrm{~cm}$ for $6 \mathrm{MV}, 10 \mathrm{MV}$ and $15 \mathrm{MV}$ photons were $67.5 \%, 73.0 \%$ and $77.0 \%$ respectively and they were within $\pm 0.7 \%$.

The surface dose derived from the PDD for all the available photon energies were listed in the Table 4 for the field size $1 \mathrm{x}$ $1 \mathrm{~cm}^{2}$ to $40 \times 40 \mathrm{~cm}^{2}$. Due to the absence of the flattening filter the beam softening were observed for the 6 FFF and $10 \mathrm{FFF}$ beam compared to the $6 \mathrm{MV}$ and $10 \mathrm{MV}$ flatten beam which resulted in the increase skin dose in the $6 \mathrm{FFF}$ and $10 \mathrm{FFF}$ beam compared to the flatten beam. There is an increase of $7.8 \%$ and $10.8 \%$ skin dose for the field size $10 \times 10 \mathrm{~cm}^{2}$ of 6 FFF and $10 \mathrm{FFF}$ compared to the flatten $6 \mathrm{MV}$ and $10 \mathrm{MV}$ beam. As the beam energy increases the skin dose decreased, for the filed size of $10 \times 10 \mathrm{~cm}^{2}$ the skin dose were $6 \mathrm{MV}$ (49.2\%), $6 \mathrm{FFF}(57.1 \%), 10 \mathrm{MV}(33.5 \%), 10 \mathrm{FFF}(44.3 \%)$ and $15 \mathrm{MV}(30.6 \%)$ respectively. The skin doses also increases with increase in the field sizes for all the available photon beam energies. 


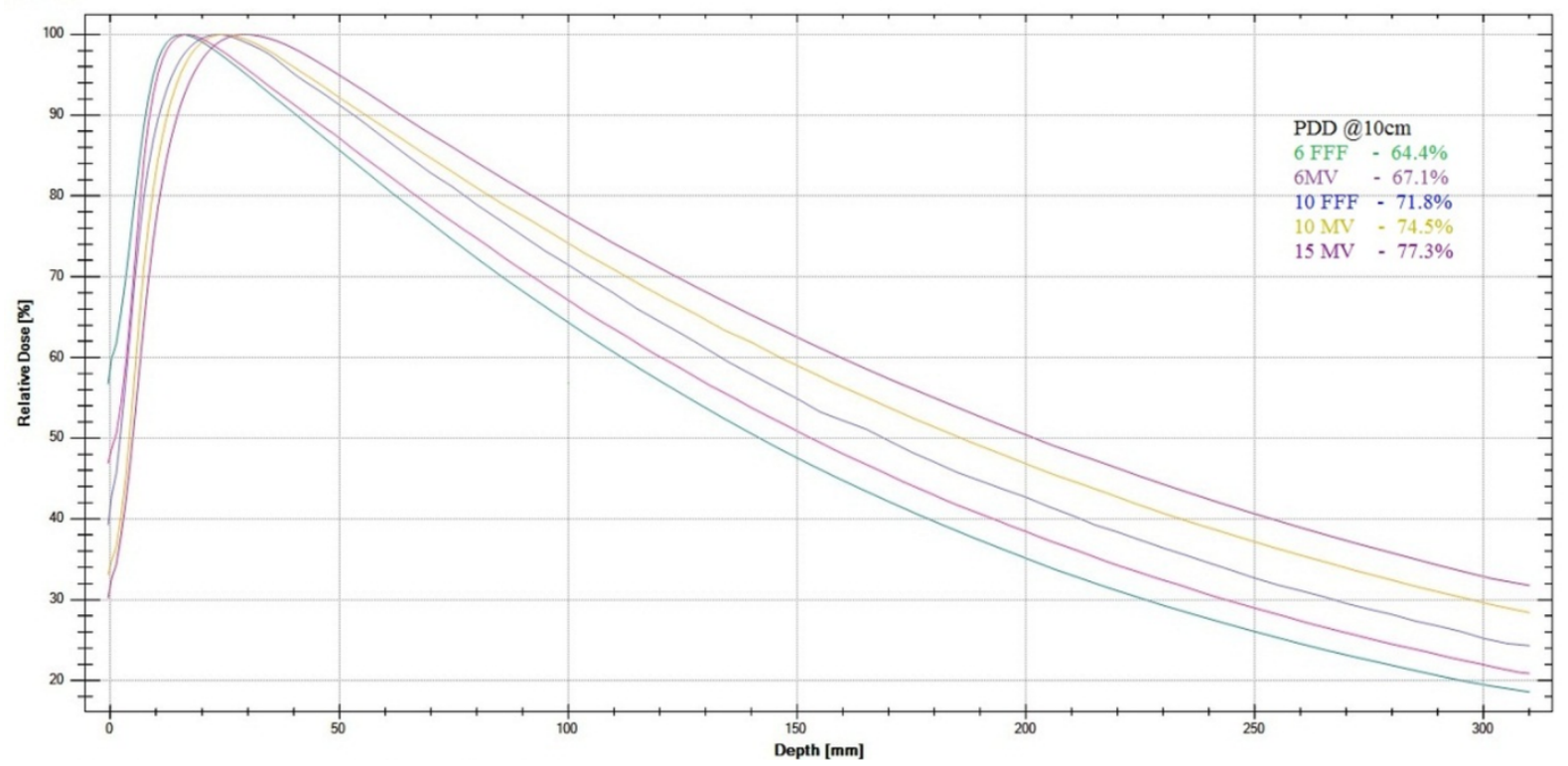

Figure 4. PDD of $10 \times 10 \mathrm{~cm}^{2}$ square field size for all the photon beams

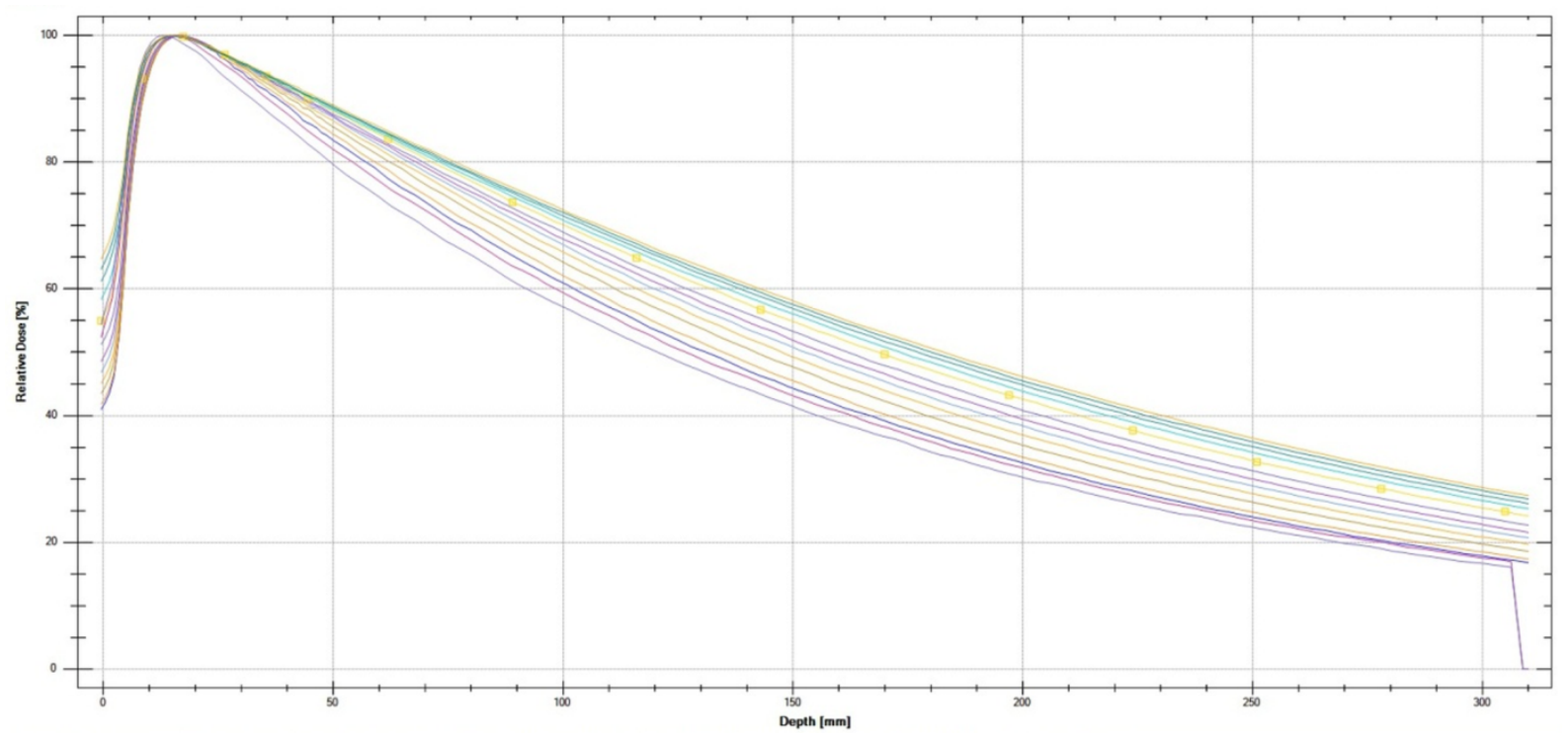

Figure 5. PDD of $6 \mathrm{MV}$ photon beam for square field sizes $1 \times 1 \mathrm{~cm}^{2}$ to $40 \times 40 \mathrm{~cm}^{2}$

Table 4. Surface dose for various photon beams versus square field sizes

\begin{tabular}{|c|c|c|c|c|c|}
\hline \multirow{2}{*}{$\begin{array}{c}\text { Field Size } \\
\mathrm{cm} \times \mathrm{cm}\end{array}$} & \multicolumn{5}{|c|}{ Surface Dose (Ds) } \\
\hline & $6 \mathrm{MV}$ & 6 FFF & $10 \mathrm{MV}$ & $10 \mathrm{FFF}$ & $15 \mathrm{MV}$ \\
\hline $1 \times 1$ & $39.5 \%$ & $48.7 \%$ & $21.8 \%$ & $34.8 \%$ & $18.3 \%$ \\
\hline $2 \times 2$ & $41.1 \%$ & $51.3 \%$ & $24.1 \%$ & $37.2 \%$ & $20.2 \%$ \\
\hline $3 \times 3$ & $42.3 \%$ & $52.5 \%$ & $25.5 \%$ & $38.9 \%$ & $21.4 \%$ \\
\hline $4 \times 4$ & $44.1 \%$ & $53.2 \%$ & $26.2 \%$ & $40.1 \%$ & $22.1 \%$ \\
\hline $6 \times 6$ & $45.7 \%$ & $54.5 \%$ & $28.5 \%$ & $41.5 \%$ & $24.7 \%$ \\
\hline $8 \times 8$ & $47.5 \%$ & $55.8 \%$ & $31.0 \%$ & $42.9 \%$ & $27.6 \%$ \\
\hline $10 \times 10$ & $49.2 \%$ & $57.1 \%$ & $33.5 \%$ & $44.3 \%$ & $30.6 \%$ \\
\hline $15 \times 15$ & $51.8 \%$ & $59.8 \%$ & $39.3 \%$ & $47.1 \%$ & $37.4 \%$ \\
\hline $20 \times 20$ & $55.6 \%$ & $61.9 \%$ & $44.4 \%$ & $49.4 \%$ & $43.3 \%$ \\
\hline $25 \times 25$ & $59.0 \%$ & $63.7 \%$ & $48.7 \%$ & $51.1 \%$ & $48.1 \%$ \\
\hline $30 \times 30$ & $61.9 \%$ & $66.3 \%$ & $52.1 \%$ & $52.9 \%$ & $52.0 \%$ \\
\hline $35 \times 35$ & $63.8 \%$ & $67.3 \%$ & $54.7 \%$ & $53.4 \%$ & $54.6 \%$ \\
\hline $40 \times 40$ & $65.4 \%$ & $67.9 \%$ & $56.2 \%$ & $53.9 \%$ & $56.3 \%$ \\
\hline
\end{tabular}




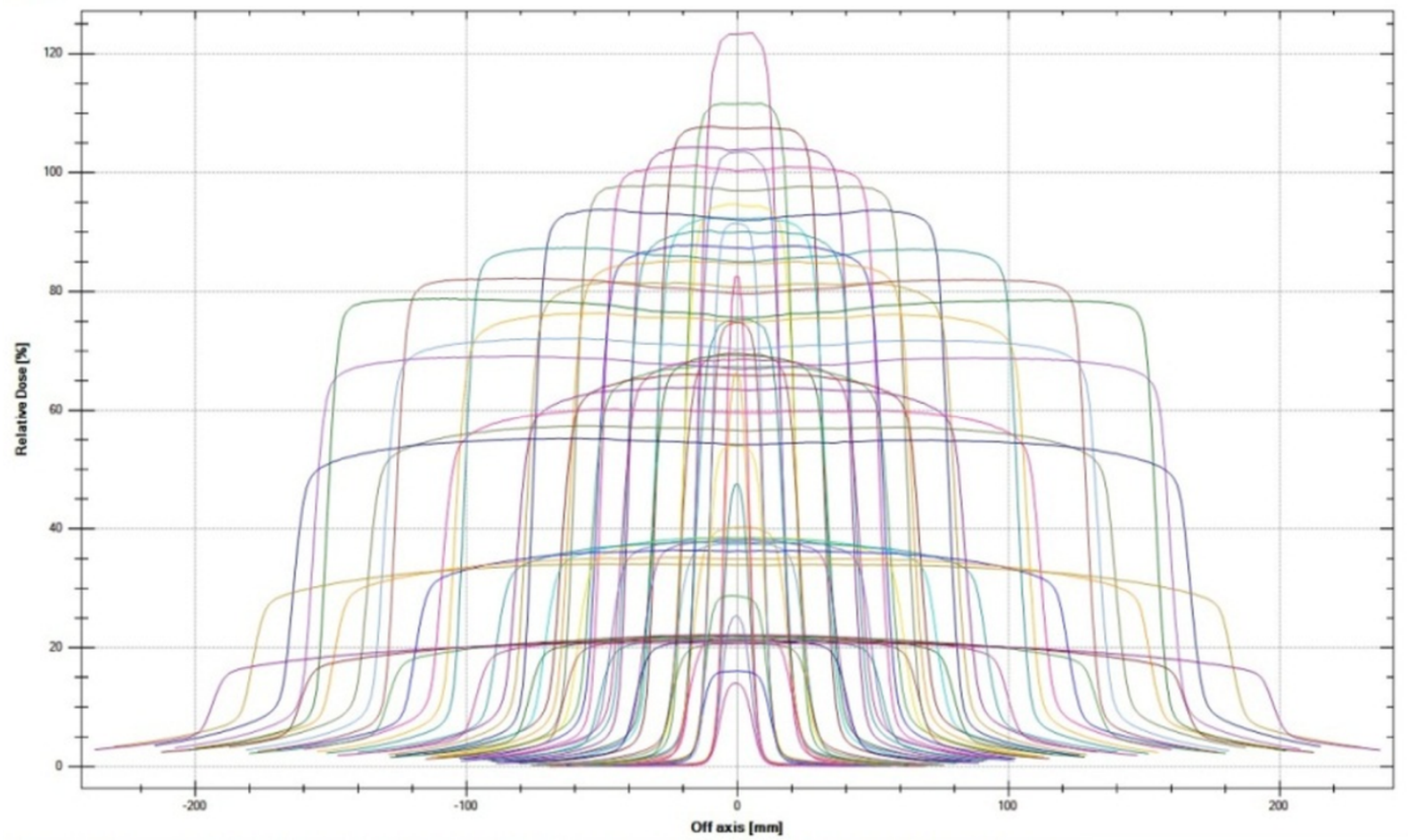

Figure 6. Crossline profile of $6 \mathrm{MV}$ photon beam for square field sizes $1 \times 1 \mathrm{~cm}^{2}$ to $30 \times 30 \mathrm{~cm}^{2}$ at Dmax, $5 \mathrm{~cm}, 10 \mathrm{~cm}, 20 \mathrm{~cm}$ and $30 \mathrm{~cm}$ depths

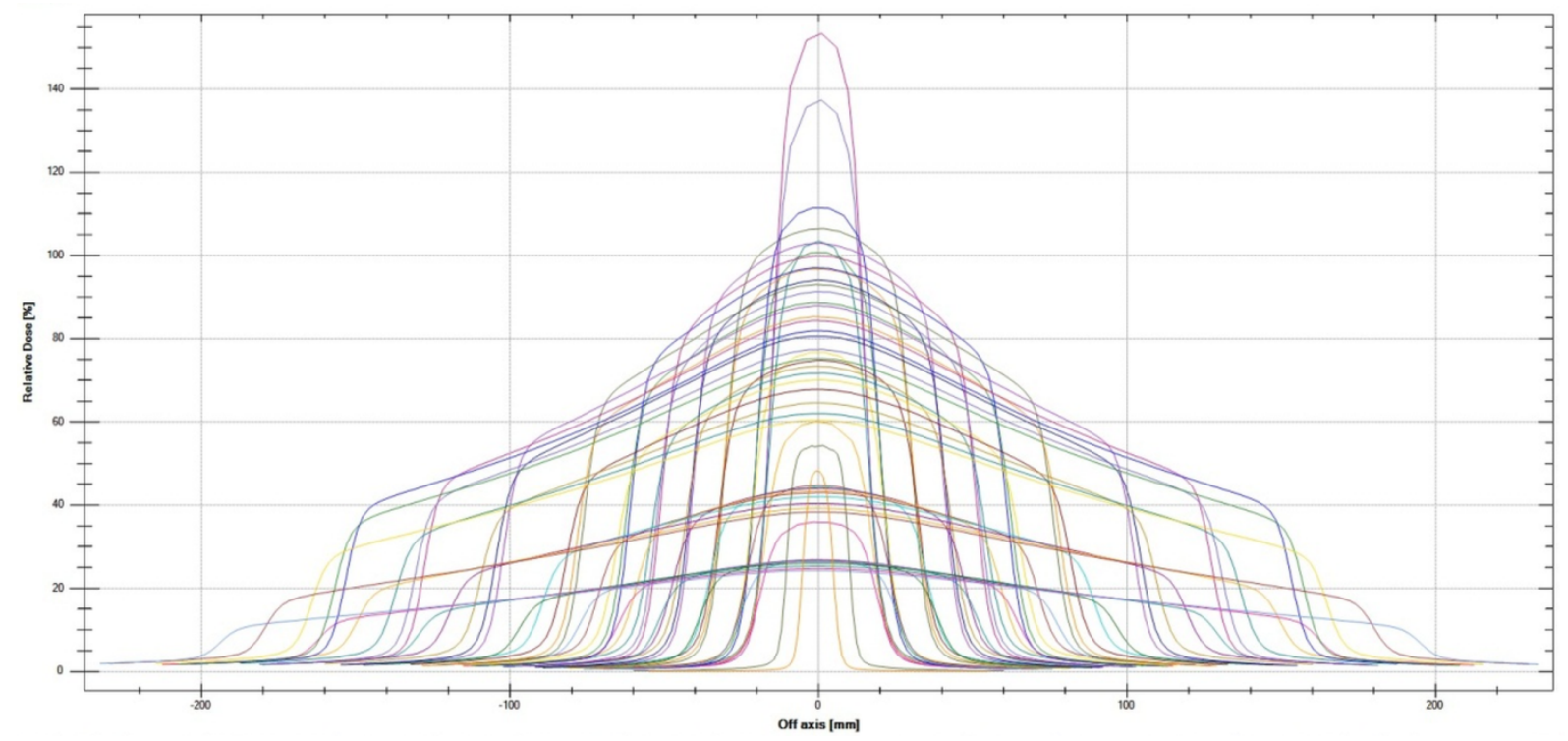

Figure 7. Crossline profile of 6 FFF photon beam for square field sizes $1 \times 1 \mathrm{~cm}^{2}$ to $30 \times 30 \mathrm{~cm}^{2}$ at Dmax, $5 \mathrm{~cm}, 10 \mathrm{~cm}, 20 \mathrm{~cm}$ and $30 \mathrm{~cm}$ depths

Table 5. Depth of Maximum, PDD at $10 \mathrm{~cm}$ Depth and Beam Quality Index for photon beams

\begin{tabular}{|c|c|c|c|c|c|c|}
\hline Energy & $\begin{array}{c}\text { Varian } D_{\max } \\
\text { Specification }(\mathrm{cm}) \\
\end{array}$ & $\begin{array}{c}\text { Measured } D_{\max } \\
(\mathrm{cm})\end{array}$ & $\begin{array}{c}\text { Varian } D_{100} \text { Specification } \\
(\%)\end{array}$ & Measured $D_{100}$ & $\begin{array}{c}\text { Golden Beam Data } \\
\text { Quality Index }\end{array}$ & $\begin{array}{c}\text { Measured } \\
\text { Quality Index } \\
\end{array}$ \\
\hline $6 \mathrm{MV}$ & $1.60 \pm 0.15$ & 1.6 & $67.2 \pm 1$ & $67.1 \%$ & 0.666 & 0.665 \\
\hline $6 \mathrm{FFF}$ & $1.50 \pm 0.15$ & 1.4 & $64.3 \pm 1$ & $64.4 \%$ & 0.630 & 0.630 \\
\hline $10 \mathrm{MV}$ & $2.40 \pm 0.15$ & 2.3 & $74.1 \pm 1$ & $74.5 \%$ & 0.738 & 0.737 \\
\hline $10 \mathrm{FFF}$ & $2.34 \pm 0.15$ & 2.2 & $71.8 \pm 1$ & $71.8 \%$ & 0.705 & 0.705 \\
\hline $15 \mathrm{MV}$ & $2.90 \pm 0.15$ & 2.9 & $77.4 \pm 1$ & $77.3 \%$ & 0.767 & 0.760 \\
\hline
\end{tabular}


The beam quality $\left(\mathrm{TPR}_{20,10}\right)$, depth of maximum $\left(\mathrm{D}_{\max }\right)$ and PDD at $10 \mathrm{~cm}\left(\mathrm{D}_{100}\right)$ were listed along with the Varian tolerance in the Table 5. All the parameters listed in the table 5 were within the tolerance of Varian customer acceptance criteria [11].

\section{Cross-line \& diagonal profiles}

The measured cross-line profiles for field size $1 \times 1$ to $30 \times 30$ $\mathrm{cm}^{2}$ for $6 \mathrm{MV}$ and $6 \mathrm{FFF}$ at $\mathrm{D}_{\max }, 5 \mathrm{~cm}, 10 \mathrm{~cm}, 20 \mathrm{~cm}$ and 30 $\mathrm{cm}$ depths were illustrated in the Figure 6 and Figure 7 respectively. The cross-line profile and the diagonal profiles of all the available beam energies were measured and imported into the Eclipse TPS using the RTPS files from the omniproaccept software. During the measurements of the cross-line and the diagonal profile, the user should make sure at-least $5 \mathrm{~cm}$ outside the absolute penumbra should be accommodated at different depths.

This will imply the absolute modeling of the dose outside the treatment field in the dose calculation kernels and hence we will have a good agreement with the dose outside the field between the TPS and the measured profiles. Due to the limitation of the dimension of the radiation field analyzer, the profiles for $35 \times 35 \mathrm{~cm}^{2}$ to $40 \times 40 \mathrm{~cm}^{2}$ shall be taken by moving the radiation field analyzer towards one side, to measure the half profile instead of the full profile, during the measurements one should take care that enough scatter is receiving in the region of interest, in other word at-least $5 \mathrm{~cm}$ margin should be there from the measurement point to include sufficient scatter.

The treatment planning system accepts the half profile and will copy the flatness of the profile to the non-measured side as a full profile.

Some user measure the diagonal profile by rotating the collimator to $45^{\circ}$ and measure below, but this is not the ideal diagonal profile. Once you rotate the collimator to $45^{\circ}$, you are still measuring the cross-line profile, hence the ideal way of measuring the diagonal profile is done by two ways, the first one is measure the diagonal profile by keeping your collimator at $0^{\circ}$ and move the detector diagonally and the other method where there is no diagonal movement option in the radiation field analyzer, you can turn the radiation field analyzer exactly at $45^{\circ}$ and measure the diagonal profile. Accurate method of measuring diagonal profile is important to model the clipped corners above $35 \times 35 \mathrm{~cm}^{2}$ field size. The part of diagonal profiles for $40 \times 40 \mathrm{~cm}^{2}$ measured at $D_{\max }, 5 \mathrm{~cm}, 10 \mathrm{~cm}, 20 \mathrm{~cm}$ and $30 \mathrm{~cm}$ depths for $6 \mathrm{MV}$ and $6 \mathrm{FFF}$ were illustrated in the Figure 8 and Figure 9 respectively.

\section{Beam Symmetry and Flatness}

According to TG 40 [12], Beam flatness (F) is assessed by finding the maximum $(\mathrm{M})$ and minimum $(\mathrm{m})$ dose point values on the beam profile within the central $80 \%$ of the beam width and then using the below Equation 5:

Beam Flatness $(F)=\frac{(M-m)}{(M+m)}$

Beam flatness tolerance according to $\mathrm{TG} 40$ is $3 \%$. Beam symmetry compares a dose profile on one side of the central axis to that on the other side. Beam symmetry is that any two dose point on a beam profile, equidistant from the central axis point, are within $2 \%$ of each other (TG 40 ).

The beam symmetry, flatness and penumbra along the inplane and cross-plane for $10 \times 10 \mathrm{~cm}^{2}$ square fields for flatten beams at $D_{\max }$ and $10 \mathrm{~cm}$ depth were listed in the Table 6.

The off axis ratio of the FFF beams for $10 \times 10 \mathrm{~cm}^{2}$ square field along the cross-plane and in-plane were listed in the Table 7.

Table 6. Beam Symmetry and Flatness for $10 \times 10 \mathrm{~cm} 2$ square field size

\begin{tabular}{|c|c|c|c|c|c|c|c|}
\hline \multirow{2}{*}{$\begin{array}{c}\text { Energy } \\
\text { (MV) }\end{array}$} & \multirow{2}{*}{$\begin{array}{c}\text { Depth } \\
\text { (cm) }\end{array}$} & \multicolumn{3}{|c|}{ In Plane } & \multicolumn{3}{|c|}{ Cross Plane } \\
\hline & & Flatness $(\%)$ & Symmetry (\%) & Penumbra (mm) & Flatness (\%) & Symmetry (\%) & Penumbra (mm) \\
\hline \multirow{2}{*}{$6 \mathrm{MV}$} & $1.6 \mathrm{~cm}\left(\mathrm{D}_{\max }\right)$ & $1.2 \%$ & $0.9 \%$ & 7.4 & $0.9 \%$ & $0.2 \%$ & 7.2 \\
\hline & $10 \mathrm{~cm}$ & $2.7 \%$ & $0.9 \%$ & 9.1 & $2.5 \%$ & $0.2 \%$ & 8.3 \\
\hline \multirow{2}{*}{$10 \mathrm{MV}$} & $2.3 \mathrm{~cm}\left(\mathrm{D}_{\max }\right)$ & $1.4 \%$ & $0.8 \%$ & 8.2 & $1.3 \%$ & $0.5 \%$ & 7.6 \\
\hline & $10 \mathrm{~cm}$ & $2.2 \%$ & $0.9 \%$ & 9.6 & $2.2 \%$ & $0.3 \%$ & 8.8 \\
\hline \multirow{2}{*}{$15 \mathrm{MV}$} & $2.9 \mathrm{~cm}\left(\mathrm{D}_{\max }\right)$ & $1.6 \%$ & $0.3 \%$ & 8.3 & $1.8 \%$ & $0.8 \%$ & 8.1 \\
\hline & $10 \mathrm{~cm}$ & $2.3 \%$ & $0.5 \%$ & 9.1 & $2.4 \%$ & $1.0 \%$ & 8.9 \\
\hline
\end{tabular}

Table 7. Off Axis Ratio for FFF beams for $10 \times 10 \mathrm{~cm}^{2}$ square field

\begin{tabular}{|c|c|c|c|c|}
\hline \multirow{2}{*}{ Energy } & \multicolumn{2}{|c|}{ Off Axis Ratio (Crossline) } & \multicolumn{2}{|c|}{ Off Axis Ratio (Inline) } \\
\hline & $-3 \mathrm{~cm}$ & $+3 \mathrm{~cm}$ & $-3 \mathrm{~cm}$ & $+3 \mathrm{~cm}$ \\
\hline $6 \mathrm{FFF}$ & 0.9555 & 0.9536 & 0.9519 & 0.9512 \\
\hline $10 \mathrm{FFF}$ & 0.9106 & 0.9095 & 0.9073 & 0.9107 \\
\hline
\end{tabular}




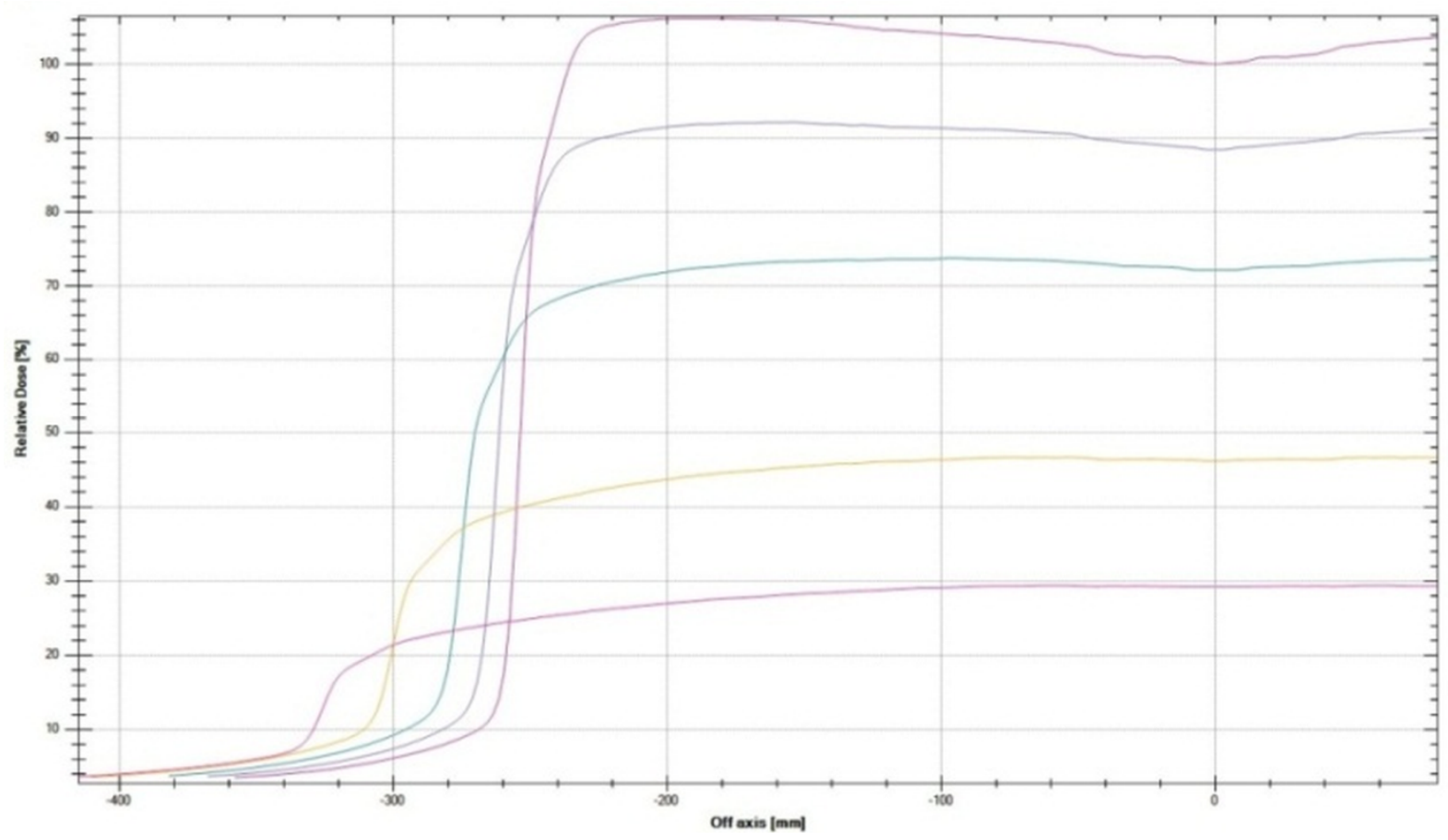

Figure 8. Diagonal profile of $6 \mathrm{MV}$ photon beam for field size of $40 \times 40 \mathrm{~cm}^{2}$ @ various depths

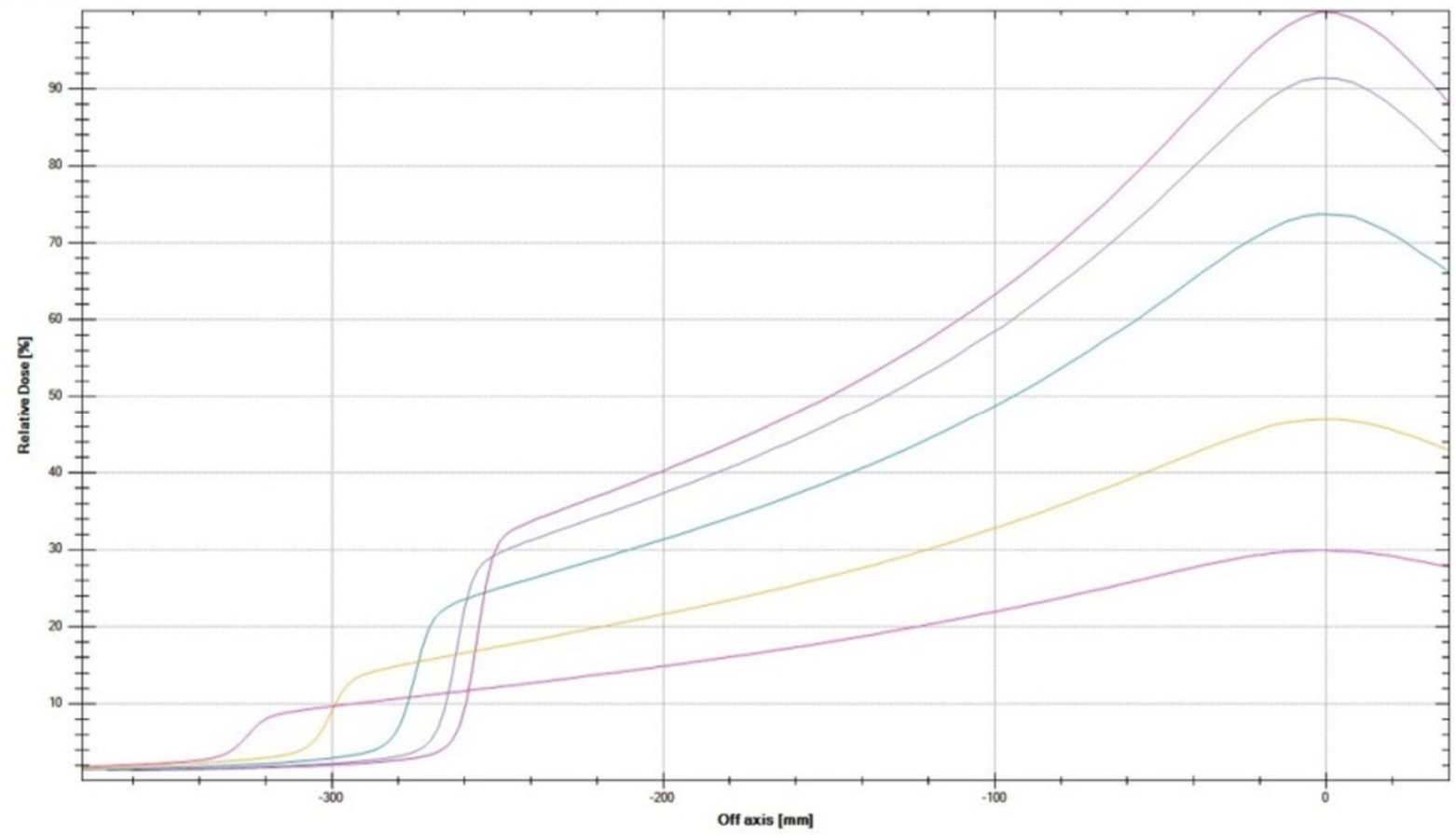

Figure 9. Diagonal profile of 6 FFF photon beam for field size of $40 \times 40 \mathrm{~cm}^{2} @$ various depths

Table 8. Comparision of outfactor for small field vs RPC data for 6 WFF, 10 WFF \& 15 WFF

\begin{tabular}{|c|c|c|c|c|c|c|c|c|c|}
\hline $\begin{array}{l}\text { Field Size } \\
(\mathrm{cm} \times \mathrm{cm})\end{array}$ & $\begin{array}{l}6 \mathrm{MV} \\
\text { (RPC) } \\
\end{array}$ & $\begin{array}{l}10 \mathrm{MV} \\
(\mathrm{RPC}) \\
\end{array}$ & $\begin{array}{l}15 \mathrm{MV} \\
(\mathrm{RPC}) \\
\end{array}$ & $6 \mathrm{MV}$ & $10 \mathrm{MV}$ & $15 \mathrm{MV}$ & $\begin{array}{c}6 \mathrm{MV} \\
(\% \text { dev }) \\
\end{array}$ & $\begin{array}{c}10 \mathrm{MV} \\
(\% \text { dev })\end{array}$ & $\begin{array}{c}15 \mathrm{MV} \\
(\% \text { dev }) \\
\end{array}$ \\
\hline $2 \times 2$ & 0.786 & 0.817 & 0.803 & 0.795 & 0.805 & 0.791 & -1.145 & 1.469 & 1.494 \\
\hline $3 \times 3$ & 0.828 & 0.867 & 0.874 & 0.835 & 0.858 & 0.863 & -0.845 & 1.038 & 1.259 \\
\hline $4 \times 4$ & 0.865 & 0.900 & 0.909 & 0.870 & 0.894 & 0.901 & -0.578 & 0.667 & 0.880 \\
\hline $6 \times 6$ & 0.921 & 0.946 & 0.951 & 0.927 & 0.942 & 0.949 & -0.651 & 0.423 & 0.210 \\
\hline
\end{tabular}


Table 9. Jaw Transmission factors for photon beams

\begin{tabular}{|c|c|c|c|c|c|}
\hline Jaw & $6 \mathrm{MV}$ & $6 \mathrm{FFF}$ & $10 \mathrm{MV}$ & 10 FFF & $15 \mathrm{MV}$ \\
\hline $\mathrm{X} 1$ & $0.42 \%$ & $0.29 \%$ & $0.41 \%$ & $0.31 \%$ & $0.42 \%$ \\
\hline $\mathrm{X} 2$ & $0.38 \%$ & $0.28 \%$ & $0.40 \%$ & $0.30 \%$ & $0.39 \%$ \\
\hline $\mathrm{Y} 1$ & $0.42 \%$ & $0.31 \%$ & $0.44 \%$ & $0.35 \%$ & $0.43 \%$ \\
\hline $\mathrm{Y} 2$ & $0.43 \%$ & $0.32 \%$ & $0.45 \%$ & $0.36 \%$ & $0.42 \%$ \\
\hline Mean Transmission & $0.41 \%$ & $0.30 \%$ & $0.43 \%$ & $0.33 \%$ & $0.42 \%$ \\
\hline
\end{tabular}

Table 10. MLC leaf transmission factors for photon beams

\begin{tabular}{|c|c|c|c|c|c|}
\hline MLC Bank & $6 \mathrm{MV}$ & 6 FFF & $10 \mathrm{MV}$ & $10 \mathrm{FFF}$ & $15 \mathrm{MV}$ \\
\hline Bank A & $1.85 \%$ & $1.42 \%$ & $2.16 \%$ & $1.57 \%$ & $2.29 \%$ \\
\hline Bank B & $1.95 \%$ & $1.44 \%$ & $2.20 \%$ & $1.59 \%$ & $2.33 \%$ \\
\hline Mean Transmission & $1.90 \%$ & $1.43 \%$ & $2.18 \%$ & $1.58 \%$ & $2.31 \%$ \\
\hline
\end{tabular}

Table 11. Dosimetric Leaf Gap for photon beams

\begin{tabular}{|c|c|c|c|c|c|}
\hline Energy & $6 \mathrm{MV}$ & 6 FFF & $10 \mathrm{MV}$ & 10 FFF & $15 \mathrm{MV}$ \\
\hline DLG (mm) & $1.75 \mathrm{~mm}$ & $1.25 \mathrm{~mm}$ & $2.32 \mathrm{~mm}$ & $1.94 \mathrm{~mm}$ & $2.31 \mathrm{~mm}$ \\
\hline
\end{tabular}

\section{Output Factor}

The output factor for the available photon energies can be measured either by SSD or SAD method, but the recommended depth of measurement should be at $10 \mathrm{~cm}$ depth. The output factor for all the energies were illustrated in the below graph (Figure 10). The measurement for small field output factor especially for field size less than $3 \times 3 \mathrm{~cm}^{2}$ for the stereotactic radiosurgery, it is preferred to measure with non-shielded diode detector preferably with electron diode detector. The recently published TRS 483 [13] report provides correction factor for output factor of the small field for various detectors for photon beam energy 6-10 MV with flattening filter and flattening filter free beam.

The measured output factors for small fields for the flatten beams were compared with the radiological Physics centers's (RPC) standard dataset [14] for small field output factors in the Table 8. The measured small field output factors were within good agreement with the RPC small field datasets with a maximum deviation of $\pm 1.5 \%$ for smaller field sizes.

Figure 10. Output factors of square field sizes for photon beams using SSD technique @ $10 \mathrm{~cm}$ depth

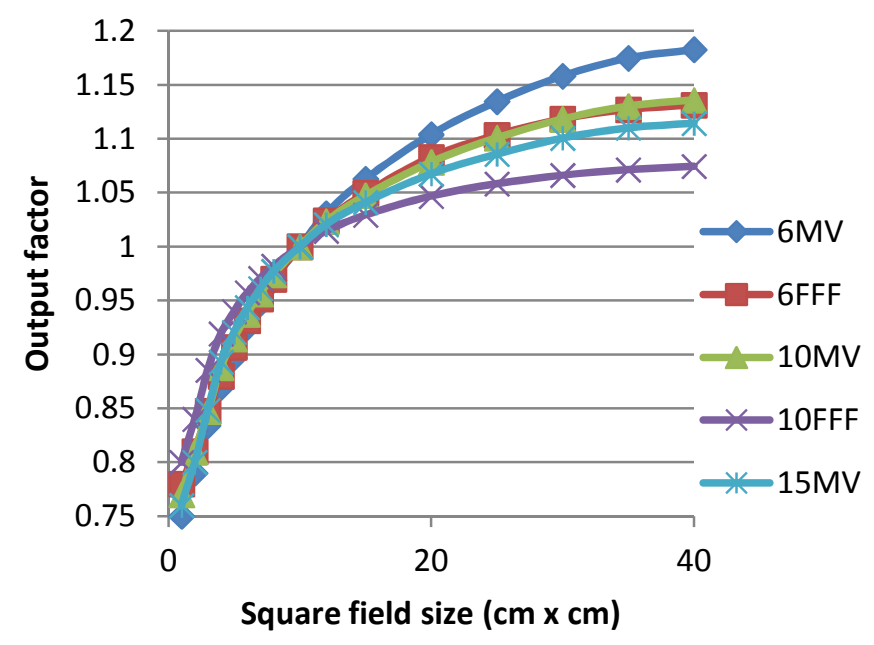

\section{Jaw transmission}

Jaw transmission for the secondary jaws has to be within $2 \%$ of the primary beam to avoid the doses outside the region of interest. The secondary collimator has asymmetric jaws function, where the $\mathrm{Y}$-jaw can override the central axis to 10 $\mathrm{cm}$, whereas the $\mathrm{X}$-jaw can override $2 \mathrm{~cm}$ across the central axis. The $\mathrm{Y}$ jaw has a more override distance to utilize for the enhanced dynamic wedges. The jaw transmissions of all the independent jaws were summarized below in the Table 9. The mean transmission has to be quoted in the Eclipse treatment planning system, the secondary jaws moves at $2 \mathrm{~cm} / \mathrm{sec}$ has to be added in the Eclipse TPS to enable the jaw tracking option in IMRT / VMAT.

\section{MLC transmission}

MLC leaf transmission of the millennium - 120 leaf were measured for all the available photon energies and listed in Table 10. The transmission of the A bank and the B bank were calculated separately and the mean of the A and B bank transmission has to recorded as a MLC transmission. The MLC transmission ranges from $1.43 \%$ for $6 \mathrm{FFF}$ and the maximum of $2.31 \%$ for $15 \mathrm{MV}$ photon beams.

\section{Dosimetric Leaf Gap}

The dosimetric leaf gap describes an effective leaf shift due to the round leaf end design, which has to incorporate to match obtain the actual fluence pattern to the TPS predicted fluence pattern. The dosimetric leaf gap for all the available photon beam energies was listed in Table 11. 6 FFF has the least dosimetric leaf gap of $1.25 \mathrm{~mm}$, whereas the $10 \mathrm{MV}$ has a maximum dynamic leaf gap of $2.32 \mathrm{~mm}$. 


\section{Conclusion}

In this report, the dosimetric data (i.e., depth dose, cross-line profiles, diagonal profiles, output factors, MLC transmission, etc.,) of the open beam for $6 \mathrm{MV}, 6 \mathrm{FFF}, 10 \mathrm{MV}, 10 \mathrm{FFF}$ and $15 \mathrm{MV}$ were measured and recorded. The beam quality parameters of the available photon beams were within the Varian acceptance tolerance and also compared with the golden beam data and they were within $\pm 1 \%$. The beam symmetry and flatness for $6 \mathrm{MV}, 6 \mathrm{FFF}, 10 \mathrm{MV}, 10 \mathrm{FFF}$ and $15 \mathrm{MV}$ were within the tolerance of the Varian acceptance criteria. The potential benefits of FFF bundles are substantial increase in dose rate, reduced field size dependence of the output, smaller and less variable MLC transmission, and sharper penumbra at shallow depths. FFF beams have a potential to reduce dose outside a field.

\section{References}

[1] Shende R, Gupta G, Patel G, Kumar S. Commissioning of TrueBeam TM Medical Linear Accelerator: Quantitative and Qualitative Dosimetric Analysis and Comparison of Flattening Filter (FF) and Flattening Filter Free (FFF) Beam. Int J Med Phys Clin Eng Radiat Oncol. 2016;5(1):55-69.

[2] Das IJ, Cheng CW, Watts RJ, et al. Accelerator beam data commissioning equipment and procedures: Report of the TG-106 of the Therapy Physics Committee of the AAPM. Med Phys. 2008;35(9) 4186-4215.

[3] Chalkley A, Heyes G. Evaluation of a Single-Crystal Diamond Detector for Relative Dosimetry Measurements on a CyberKnife. Br J Radiol. 2014;87(1035): 20130768.

[4] Dieterich S, Ford E, Pavord D, Zeng J. Practical Radiation Oncology Physics: a Companion to Gunderson \& Tepper's Clinical Radiation Oncology. Elsevier, 2016, Page 21-22.

[5] Huang Y, Willomitzer C, Zakaria GA, Hartmann GH. Experimental determination of the effective point of measurement of cylindrical ionization chambers for high-energy photon and electron beams. Phys Med. 2010;26(3):126-131.

[6] Yao W, Farr JB. Determining the optimal dosimetric leaf gap setting for rounded leaf-end multileaf collimator systems by simple test fields. J Appl Clin Med Phys. 2015;16(4):65-77.

[7] IAEA. Absorbed dose determination in external beam radiotherapy: an international code of practice for dosimetry based on standards of absorbed dose to water. Vienna: International Atomic Energy Agency, Technical Reports Series TRS-398; 2000.

[8] Almond PR, Biggs PJ, Coursey BM, et al. AAPM's TG-51 protocol for clinical reference dosimetry of high-energy photon and electron beams. Med Phys. 1999;26(9):1847-1870.

[9] Wang Y, Easterling SB, Ting JY. Ion recombination corrections of ionization chambers in flattening filter-free photon radiation. J Appl Clin Med Phys. 2012;13(5):262-268.

[10] Central axis depth dose data for use in radiotherapy. Br J Radiol Suppl. 1996;25.

[11] Installation Product Acceptance for True Beam / True Beam STx version 1.6, Document part number IPA-HT-16-J, Nov 2013

[12] Kutcher GJ, Coia L, Gillin M, et al. Comprehensive QA for radiation oncology: Report of AAPM Radiation Therapy Committee Task Group 40. Med Phys. 1994;21(4):581-618.

[13] IAEA. Dosimetry of Small Static Fields Used in External Beam Radiotherapy. Vienna: International Atomic Energy Agency, Technical Reports Series TRS-483; 2017.

[14] Followill DS, Kry SF, Qin L, et al. The Radiological Physics Center's standard dataset for small field size output factors. J Appl Clin Med Phys. 2012;13(5):3962. 